\title{
Dietary patterns associated with subclinical atherosclerosis: cross-sectional analysis of the Brazilian Longitudinal Study of Adult Health (ELSA-Brasil) study
}

\author{
Bartira Gorgulho', Mariane A Alves ${ }^{2}$ (1), Juliana A Teixeira², Roberta $\bigcirc$ Santos $^{2}$ (0), \\ Sheila Alvim de Matos ${ }^{3}$, Marcio Sommer Bittencourt ${ }^{4}$, Isabela Benseñor ${ }^{4}$, Paulo Lotufo ${ }^{4}$ \\ and Dirce Maria Marchioni ${ }^{2, *}$ \\ 'Department of Food and Nutrition, School of Nutrition, Federal University of Mato Grosso, Cuiabá, MT, Brazil: \\ ${ }^{2}$ Department of Nutrition, School of Public Health, University of São Paulo, Av. Dr. Arnaldo, 715 - Cerqueira César, \\ São Paulo - SP, CEP 01246-904, Brazil: ${ }^{3}$ Department of Collective Health, Federal University of Bahia, Salvador, BA, \\ Brazil: ${ }^{4}$ Center for Clinical and Epidemiological Research, University Hospital, University of São Paulo, São Paulo, \\ Brazil
}

Submitted 7 February 2020: Final revision received 11 December 2020: Accepted 21 December 2020: First published online 8 January 2021

\begin{abstract}
Objective: To identify dietary patterns associated with subclinical atherosclerosis measured as coronary artery calcification (CAC).

Design: Cross-sectional analysis of data from the Brazilian Longitudinal Study of Adult Health. Dietary data were assessed using a FFQ, and a principal component factor analysis was used to derive the dietary patterns. Scree plot, eigenvalues $>1$ and interpretability were considered to retain the factors. CAC was measured using a computed tomography scanner and an electrocardiography-gated prospective Ca score examination and was categorised into three groups based on the CAC score: 0,1-100 and >100 Agatston units. Multinomial regression models were conducted for dietary patterns and CAC severity categories.

Setting: Brazil, São Paulo, 2008-2010.

Participants: Active and retired civil servants who lived in São Paulo and underwent a CAC exam were included ( $n$ 4025).

Results: Around $10 \%$ of participants (294 men, 97 women) had a detectable CAC (>0), 6.5\% (182 men, 73 women) had a CAC of 1-100 and 3.5\% (110 men, 23 women) had a CAC $>100$. Three dietary patterns were identified: convenience food, which was positively associated with atherosclerotic calcification; plantbased and dairy food, which showed no association with CAC; and the traditional Brazilian food pattern (rice, legumes and meats), which was inversely associated with atherosclerotic calcification.

Conclusions: Our results showed that a dietary pattern consisting of traditional Brazilian foods could be important to reducing the risk of atherosclerotic calcification and prevent future cardiovascular events, whereas a convenience dietary pattern was positively associated with this outcome.
\end{abstract}

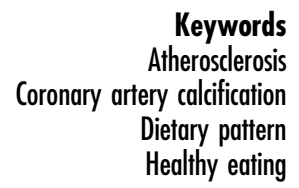

The global prevalence of coronary artery disease was 154 million in 2016, representing $32.7 \%$ of the global burden of CVD and $2 \cdot 2 \%$ of the overall global burden of disease ${ }^{(1)}$. Assessment of risk for atherosclerotic CVD and primary CVD prevention makes up a significant part of a clinician's daily practice ${ }^{(2)}$.

The coronary artery calcification (CAC) score is a marker of subclinical atherosclerosis, which is capable of predicting cardiovascular events in individuals with no previous $\mathrm{CVD}^{(3,4)}$. The CAC score detected by cardiac computed tomography is an accurate non-invasive marker used to assess atherosclerosis in the coronary arteries, providing information on underlying pathologic changes within them, and enabling a detailed assessment of the subclinical disease ${ }^{(5,6)}$. Coronary events are directly proportional to calcified plaque burden and hence total plaque 
burden $^{(2)}$, and CAC score categories are associated with CHD and incident stroke, according to two systematic reviews and meta-analyses ${ }^{(7,8)}$.

The CAC score has great potential to guide clinical recommendations and has been applied to regulate the adequate use of anti-atherosclerosis drugs. Moreover, CAC score evaluations in clinical practice have led to the increased use of aspirin, blood pressure and cholesterol therapies, and improved adherence to statin therapy in at-risk patients ${ }^{(9)}$.

According to WHO, most CVD can be prevented by addressing behavioural risk factors such as tobacco use, unhealthy diet and obesity. Whilst some studies have investigated the association between CAC and specific beverages (i.e. coffee and sugar-sweetened beverages) ${ }^{(10,11)}$ and a review reported evidence for micronutrients ${ }^{(12)}$, few studies ${ }^{(13,14)}$ have evaluated the relationship between dietary patterns and CAC. Dietary pattern analysis, which reflects the complexity of dietary intake, accounts for cumulative and interactive effects and reflects actual eating habits and might be useful in the context of prevention of $\mathrm{CVD}^{(15,16)}$. It is plausible that adherence to a healthy dietary pattern would be positively associated with a low prevalence and severity of subclinical atherosclerosis as measured by the CAC score, a hypotheses supported by the literature $^{(17,18)}$.

The Brazilian Longitudinal Study of Adult Health (ELSABrasil) is an ongoing multicentre cohort study focused on chronic diseases, particularly CVD, in a large admixed population. In this context, the objective of this study was to identify dietary patterns that are associated with subclinical atherosclerosis measured as CAC during the baseline examination of ELSA-Brasil participants.

\section{Methods}

The ELSA-Brasil was described previously ${ }^{(19,20)}$. Briefly, 15105 civil servants aged 35-74 years were recruited from five universities and one research institute located in different regions of Brazil. For this cross-sectional analysis of baseline data, only participants living in São Paulo who underwent a CAC score examination were included. The baseline examinations were performed in 2008-2010. The exclusion criteria were current or recent pregnancy ( $<4$ months prior to the first interview), intention to quit working at the institution in the near future, severe cognitive or communication impairment and, if retired, residence outside of a study centre's corresponding metropolitan area, history of cardiac diagnoses (myocardial infarction, stroke or coronary revascularisation) for whom information was missing for any covariate, or who had an energy intake lower than the 1st percentile or higher than the 99th percentile were excluded ${ }^{(21)}$. After exclusions, 4025 individuals were analysed in this study (Fig. 1).

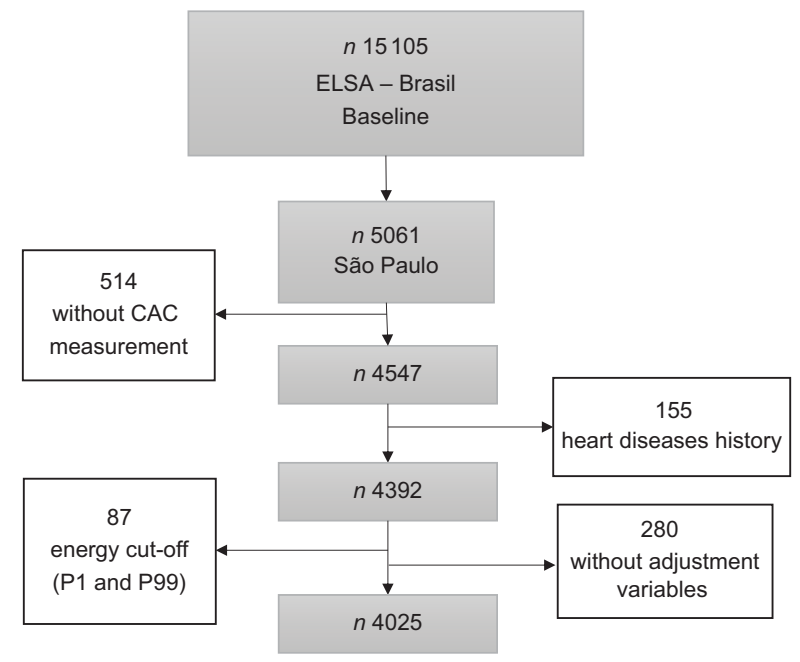

Fig. 1 Sample size and exclusion criteria, Brazilian Longitudinal Study of Adult Health (ELSA-Brasil) 2019

Compared with the Brazilian general population, the ELSA-Brasil participants had higher monthly incomes, high levels of education attainment and better access to health care $^{(20)}$. However, they were selected according to the study aims, including a similar number of participants with occupations classified as unskilled, technical/clerical, and faculty and professional staff, permitting a gradient of socio-economic position across the sample. Each participant was interviewed at their workplace and visited the research centre for clinical exams according to standard protocols ${ }^{(22)}$. At each site, the interview and clinical examination were performed by trained personnel with strict quality control.

During interviews, the participants answered questions about their sociodemographic information, health and medical history, occupational exposure, family history of disease, reproductive and mental health, health care, psychological factors, body image and weight history, food consumption, smoking, alcohol consumption, physical activity, medication use and cognitive function. The physical examination included measurements of height, weight and blood pressure using standard protocols. Height and weight were measured using a stadiometer ( $\left.\mathrm{Seca}^{\circledR}\right)$ and a digital scale $\left(\text { Toledo }^{\circledR}\right)^{(23)}$, respectively. Participants at the ELSA-MEC site in São Paulo were invited to undergo a computed tomography examination for the quantification of CAC.

The ELSA-Brasil protocol was approved at all six centres by the respective institutional review boards addressing research in human participants. All participants signed a written informed consent form.

\section{Diet}

Dietary data were assessed using a validated FFQ composed of 114 food items applied by interviewers to evaluate each participant's diet in the past 12 months covering three 
sections: (1) food products/food preparations; (2) measures of consumed products and (3) consumption frequencies with eight response options including 'more than 3 times a day', '2 to 3 times a day', 'once a day', '5 to 6 times a week', '2 to 4 times a week', 'once a week', ' 1 to 3 times a month' and 'never/rarely' ${ }^{\text {(24,25). }}$

The foods in the questionnaire were then classified into the following food groups: processed meat (ham, bacon, hamburger and sausage), snacks, candies, potatoes and tubers, sugar beverages, breads and cakes, eggs, pasta, butter, poultry, fruit, vegetables, oatmeal, milk, yogurt, nuts, cheese, rice, legumes, red meat and fish. These groupings were based on their nutritional content similarities.

\section{Coronary artery calcification measurement}

All CAC examinations were performed using a sixty-fourdetector row computed tomography scanner (Brilliance 64, Philips Healthcare). After scout images were collected, each patient underwent an electrocardiography-gated prospective CAC score examination with a tube potential of $120 \mathrm{kV}$ and a tube current adjusted to the body habitus. Images were reconstructed in 2.5-mm-thick slices using standard filtered back projection ${ }^{(26)}$. Each CAC is expressed in Agatston units ${ }^{(27)}$, and the percentiles were blindly evaluated by an experienced cardiologist using semiautomatic software (Calcium Scoring, Philips Workstation). CAC severity was further categorised into $0,1-100$ and $>100$ (Agatston units) $^{(7,8,28)}$.

\section{Statistical analysis}

In addition to observation of the correlation matrix, principal component factor analysis was used to derive the dietary patterns (factors) based on the frequency consumption of the nineteen food groups categorised according to similar nutritional composition and culinary use ${ }^{(29)}$. The criteria used to retain the factors were eigenvalue $>1$, scree plot shape and interpretability. Varimax rotation was applied to achieve a simpler structure with greater interpretability. The factor labels were assigned to each pattern retained based on an approximate description of the food items that were most highly represented (factor loadings $\geq 0 \cdot 40$ ). The applicability of the data to the factor analysis was verified using the Kaiser-Meyer-Olkin test considering values $>0.50$ as acceptable.

Linear regression models between dietary patterns and cardiovascular risk factors were created for the sample. The dietary intake of nutrients that correlated with the outcome of interest, including total fat, saturated fat, fibre and energy, was also used as adjustment variables. Urinary $\mathrm{Na}(\mathrm{g} / \mathrm{d})$ was used as a proxy for iodine consumption ${ }^{(30)}$.

Multinomial regression models were used to evaluate the association between CAC severity categories and dietary patterns similar to those applied in other studies of the CAC score ${ }^{(31,32)}$. In this way, the dependent variable was categorised as CAC 0, CAC $1-100$ and CAC $\geq 100$.
The models were adjusted by the dietary variables used in the linear regression models plus: age (35-59 years or $60+$ years); sex (male or female); self-reported race/colour (white or not white); education length ( $\leq 8$ years or $9+$ years); smoking status (non-smoker, ex-smoker or smoker) and sporadic excessive alcohol consumption dichotomised (yes or no) according to the amount ingested per week (men $\geq 210 \mathrm{~g}$; women $\geq 140 \mathrm{~g}$ ); level of physical activity during leisure classified as low, moderate or vigorous according to the International Physical Activity Questionnaire $(\geq 150 \mathrm{~min} /$ week of moderate activity or $\geq 75 \mathrm{~min} /$ week of vigorous activity) $)^{(33,34)}$; anthropometric status by BMI in $\mathrm{kg} / \mathrm{m}^{2}$ (low weight, eutrophic, overweight or obese) according to the cut-off points recommended by the WHO (overweight: $\mathrm{BMI} \geq 25.0-29.9 \mathrm{~kg} / \mathrm{m}^{2}$; obese: $\left.\mathrm{BMI} \geq 30 \mathrm{~kg} / \mathrm{m}^{2}\right)^{(35)}$; hypertension (yes or no) according to a systolic blood pressure $\geq 140 \mathrm{mmHg}$ and/or diastolic blood pressure $\geq 90 \mathrm{mmHg}$, or use of drugs for treating hypertension; diabetes (yes or no) obtained from data on post-prandial glycaemia, glycated $\mathrm{Hb}$, use of medications for treating diabetes and previous diagnosis of diabetes; and dyslipidaemia (yes or no) obtained from a previous diagnosis of the disease or the use of lipid-lowering medications.

All analyses were performed using Stata Statistical Software (release 14, 2015, StataCorp LP), and the level of significance was set at $5 \%$. For all situations, a proportional odds model for each dietary pattern was used.

\section{Results}

Among the 4025 respondents, around $10 \%$ (292 men and 96 women) had a CAC score $>0$, suggesting the presence of some CAC. The sample description by CAC score classification is shown in Table 1.

In relation to food consumption, three dietary patterns were retained, representing $32 \%$ of accumulated variance, with a Kaiser-Meyer-Olkin of 0.70 (Table 2). The first pattern was positively characterised by convenience foods (processed meat, snacks, candies, potatoes and tubers, sugary beverages, breads and cakes); the second was positively characterised by plant-based and dairy foods (fruits, vegetables, oatmeal, milk, yoghurt and nuts) and the third was positively characterised by rice, legumes and red meat. Table 3 shows the observed associations between dietary patterns and cardiovascular risk factors.

The multinomial regression model suggested that increased adherence to the convenience foods dietary pattern was associated with an increased risk of developing CAC. For each increase in the dietary pattern score, the odds of having a CAC score $>100$ increased by $33 \%$ (OR $1 \cdot 33$; $95 \%$ CI $1 \cdot 02,1 \cdot 74, P=0 \cdot 036)$ in the complete model (model 6). In contrast, high adherence to the Brazilian traditional dietary pattern decreased the odds of having a CAC 
Table 1 Sample description by Coronary Artery Calcium Score, São Paulo (SP), Brasil, 2019

\begin{tabular}{|c|c|c|c|c|c|c|c|c|c|}
\hline & \multicolumn{2}{|c|}{ Total } & \multicolumn{2}{|c|}{$\mathrm{CAC}=0$} & \multicolumn{2}{|c|}{ CAC 1-100 } & \multicolumn{2}{|c|}{$\mathrm{CAC}>100$} & \multirow[b]{2}{*}{$P^{*}$} \\
\hline & $n$ & $\%$ & $n$ & $\%$ & $n$ & $\%$ & $n$ & $\%$ & \\
\hline Sex & & & & & & & & & $<0.001$ \\
\hline Men & 1848 & $45 \cdot 91$ & 1556 & $42 \cdot 78$ & 182 & 71.37 & 110 & $82 \cdot 71$ & \\
\hline Women & 2177 & $54 \cdot 87$ & 2081 & $57 \cdot 22$ & 73 & 28.63 & 23 & $17 \cdot 29$ & \\
\hline Age & & & & & & & & & $<0.001$ \\
\hline Young adults ( $34-59$ years) & 3349 & 83.20 & 3154 & $86 \cdot 72$ & 147 & $57 \cdot 65$ & 48 & 36.09 & \\
\hline Old adults (60 years or more) & 676 & $16 \cdot 80$ & 483 & $13 \cdot 28$ & 108 & $42 \cdot 35$ & 85 & 63.91 & \\
\hline Race/colour self-reported & & & & & & & & & 0.032 \\
\hline White & 2340 & $58 \cdot 14$ & 2100 & $57 \cdot 74$ & 148 & $58 \cdot 04$ & 92 & $69 \cdot 17$ & \\
\hline No white & 1685 & 41.86 & 1537 & $42 \cdot 26$ & 107 & 41.96 & 41 & $30 \cdot 83$ & \\
\hline Education & & & & & & & & & 0.005 \\
\hline Until 8 years & 600 & 14.90 & 521 & $14 \cdot 32$ & 54 & $21 \cdot 18$ & 25 & $18 \cdot 80$ & \\
\hline 9 years or more & 3425 & $85 \cdot 10$ & 3116 & $85 \cdot 68$ & 201 & 78.82 & 108 & $81 \cdot 20$ & \\
\hline Overweight or obese & & & & & & & & & 0.007 \\
\hline No & 1398 & 34.73 & 1288 & 35.41 & 79 & $30 \cdot 98$ & 31 & $23 \cdot 31$ & \\
\hline Yes & 2627 & $65 \cdot 27$ & 2349 & 64.59 & 176 & 69.02 & 102 & $76 \cdot 69$ & \\
\hline Smoking & & & & & & & & & $<0.001$ \\
\hline Non-smokers & 2157 & 53.59 & 2000 & 54.99 & 115 & $45 \cdot 10$ & 42 & 31.58 & \\
\hline Ex-smoker & 1228 & 30.51 & 1076 & 29.58 & 85 & 33.33 & 67 & $50 \cdot 38$ & \\
\hline Current smoker & 640 & $15 \cdot 90$ & 561 & $15 \cdot 43$ & 55 & 21.57 & 24 & $18 \cdot 04$ & \\
\hline Excessive alcohol consumption sporadic & & & & & & & & & 0.200 \\
\hline No & 3633 & $90 \cdot 26$ & 3292 & $90 \cdot 51$ & 226 & $88 \cdot 63$ & 115 & 85.47 & \\
\hline Yes & 392 & $9 \cdot 74$ & 345 & 9.49 & 29 & $11 \cdot 37$ & 18 & 13.53 & \\
\hline Physical activity & & & & & & & & & 0.209 \\
\hline Low & 3166 & 78.66 & 2877 & $79 \cdot 10$ & 191 & 74.90 & 98 & 73.68 & \\
\hline Moderate & 525 & 13.04 & 460 & 12.65 & 43 & $16 \cdot 86$ & 22 & $16 \cdot 54$ & \\
\hline Vigorous & 334 & $8 \cdot 30$ & 300 & 8.25 & 21 & $8 \cdot 24$ & 13 & $9 \cdot 78$ & \\
\hline Hypertension & & & & & & & & & $<0.001$ \\
\hline No & 2798 & 69.52 & 2633 & $72 \cdot 39$ & 112 & 43.92 & 53 & 39.85 & \\
\hline Yes & 1227 & 30.48 & 1004 & $27 \cdot 61$ & 143 & $56 \cdot 08$ & 80 & $60 \cdot 15$ & \\
\hline Diabetes & & & & & & & & & $<0.001$ \\
\hline No & 3216 & 79.90 & 2966 & 81.55 & 175 & 68.63 & 75 & $56 \cdot 39$ & \\
\hline Yes & 809 & $20 \cdot 10$ & 671 & 18.45 & 80 & 31.37 & 58 & $43 \cdot 61$ & \\
\hline Dyslipidaemia & & & & & & & & & $<0.001$ \\
\hline No & 1749 & 43.45 & 1624 & 44.65 & 83 & 32.55 & 42 & 31.58 & \\
\hline Yes & 2276 & 56.55 & 2013 & $55 \cdot 35$ & 172 & $67 \cdot 45$ & 91 & $68 \cdot 42$ & \\
\hline
\end{tabular}

${ }^{*}$ Chi-square test.

score $>100($ OR $0 \cdot 76 ; 95 \%$ CI 0.60, $\cdot 0 \cdot 97, P=0 \cdot 027)$, indicating that it is a possible protective factor (Table 4 ).

\section{Discussion}

In this cross-sectional analysis of an adult population that participated in the ELSA-Brasil, a higher adherence to the dietary pattern characterised by the consumption of processed meat, snacks, candies, potatoes and tubers, sugary beverages, and bread and cakes was positively associated with a higher CAC score, while a higher adherence to the dietary pattern characterised by rice, legumes and red meat was inversely associated with CAC score.

Although the relationship between dietary patterns and CAC score has been little explored, similar studies have investigated this association. A cross-sectional study identified that a dietary pattern derived by reduced rank regression, which was high in processed meat, fats and oils, and soda, similar to the convenience dietary pattern of the current study, was associated with the presence of CAC (CAC score $>1$ ) in a multi-ethnic population aged $45-84$ years. In the same study, a similar dietary pattern derived by factor analysis was not associated with CAC score ${ }^{(13)}$. A crosssectional study of middle-aged Spanish adults found a dietary pattern characterised by the consumption of red and processed meat, pre-made foods, snacks, alcohol and sugar-sweetened beverages increased the odds of presenting with subclinical atherosclerosis (CAC score $\geq 1$ ) by $31 \%$ compared with subjects following a Mediterranean $\operatorname{diet}^{(36)}$. Considering the presence of the sugary beverage food group in the convenience dietary pattern, we highlight a cross-sectional study of Korean workers that reported a $27 \%$ higher odds of a CAC score $>0$ for individuals with the highest consumption of sugary beverage consumption ( $\geq 5$ drinks/week) $v$. non-consumers. This study also indicates that individuals with a higher intake of sugarsweetened beverages were more likely to consume larger amounts of energy, fruits, vegetables, red and processed meat, sugary foods and alcohol ${ }^{(10)}$.

Direct comparisons between these studies should be made with caution since the respective dietary patterns were identified using different methodological approaches. Even so, our findings and those of the aforementioned 
Table 2 Dietary patterns factor loadings, São Paulo (SP), Brasil, 2019

\begin{tabular}{|c|c|c|c|}
\hline \multirow[b]{2}{*}{ Food group } & \multicolumn{3}{|c|}{ Dietary pattern* } \\
\hline & Convenience & $\begin{array}{l}\text { Plant-based and } \\
\text { dairy }\end{array}$ & $\begin{array}{l}\text { Brazilian } \\
\text { traditional }\end{array}$ \\
\hline Processed meat & 0.54 & -0.03 & 0.04 \\
\hline Snacks & 0.51 & -0.08 & -0.08 \\
\hline Candies & 0.49 & -0.01 & -0.15 \\
\hline $\begin{array}{l}\text { Potatoes and } \\
\text { tubers }\end{array}$ & 0.46 & 0.02 & 0.12 \\
\hline $\begin{array}{l}\text { Sugary } \\
\text { beverages }\end{array}$ & 0.44 & -0.24 & 0.16 \\
\hline Breads and cakes & 0.41 & 0.29 & -0.05 \\
\hline Eggs & 0.39 & -0.06 & 0.17 \\
\hline Pasta & 0.36 & -0.04 & -0.07 \\
\hline Butter & 0.32 & -0.02 & 0.26 \\
\hline Poultry & 0.31 & 0.23 & 0.23 \\
\hline Fruits & -0.10 & 0.70 & -0.05 \\
\hline Vegetables & -0.04 & 0.65 & 0.10 \\
\hline Oatmeal & -0.01 & 0.56 & -0.14 \\
\hline Milks and yogurts & 0.13 & 0.47 & 0.02 \\
\hline Nuts & 0.07 & 0.41 & -0.34 \\
\hline Cheese & 0.33 & 0.39 & -0.34 \\
\hline Fish & 0.24 & 0.27 & 0.02 \\
\hline Rice & -0.04 & -0.01 & 0.80 \\
\hline Legumes & 0.04 & -0.03 & 0.79 \\
\hline Red meat & 0.27 & -0.02 & 0.41 \\
\hline$\%$ variance & 11.00 & $10 \cdot 00$ & $10 \cdot 00$ \\
\hline $\begin{array}{l}\% \text { accumulated } \\
\text { variance }\end{array}$ & 11.00 & 21.00 & 31.00 \\
\hline
\end{tabular}

Bold values indicate a factor loading $\geq 4 \cdot 0$.

*Kaiser-Meyer-Olkin 0.70.

studies suggest that individuals with higher adherence to a dietary pattern marked by processed meat, foods and beverages with high levels of saturated fat and sugar, which are poor in fibre and micronutrients, had a greater chance of presenting with subclinical atherosclerosis. A longitudinal study conducted by Canhada et al. ${ }^{(37)}$ also reported that a greater consumption of ultra-processed foods (NOVA classification) was associated with a higher risk of large weight (27\%) and waist circumference gains (33\%) in the ELSA-Brasil population ${ }^{(37)}$.

Our results also showed an inverse association between the traditional Brazilian dietary pattern and CAC score. This may be explained by the presence of legume food groups in this dietary pattern. In Brazil, legumes are traditionally consumed with rice and the nutritional value and accessibility of this combination are recognised ${ }^{(38)}$. Although white rice is a refined processed carbohydrate associated with an increased risk of type 2 diabetes and cardiometabolic diseases, combined rice and beans have an attenuated glycaemic response compared with rice alone ${ }^{(39,40)}$.

Legumes are rich in fibre, both insoluble and soluble, low in fat, and a good source of digestible protein, indicating that this nutrient profile can be responsible for health benefits $^{(41)}$, as well as improving the lipid profile ${ }^{(42)}$. There is no clear evidence of the relationship between legume consumption and CAC score, and we have inconclusive results regarding their dietary intake ${ }^{(43)}$. However, some studies have identified benefits for cardiovascular health, including a systematic review that found a protective role of this food group against $\mathrm{CHD}^{(44)}$.

Another cross-sectional study identified out-of-home eating patterns in the Brazilian population and its relationship with the overall nutritional quality of the Brazilian diet, independent of energy consumption, sociodemographic and socio-economic characteristics. It was observed that the fifth quintile of adherence to a dietary pattern carried on rice, legumes and meat was associated with a decrease in energy density, percentage of energies from carbohydrates, saturated fat, trans-fat, free sugar and $\mathrm{Ca}^{(45)}$. This can explain the inverse association between the traditional Brazilian dietary pattern and CAC score considering that an excessive intake of saturated fat and trans-fat increases the risk of CVD mortality ${ }^{(46)}$.

Table 3 Linear regression models between dietary patterns and cardiovascular risk factors, São Paulo (SP), Brasil, 2019

\begin{tabular}{|c|c|c|c|c|c|c|}
\hline & \multicolumn{6}{|c|}{ Dietary pattern } \\
\hline & \multicolumn{2}{|c|}{ Convenience* $^{*}$} & \multicolumn{2}{|c|}{ Plant-based and dairy* } & \multicolumn{2}{|c|}{ Brazilian Traditional } \\
\hline & $\beta \dagger$ & $P$ & $\beta \dagger$ & $P$ & $\beta \dagger$ & $P$ \\
\hline Sex (men) & $-0 \cdot 181$ & $<0.001$ & -0.535 & $<0.001$ & -0.052 & 0.089 \\
\hline Age (60 years or more) & -0.001 & 0.678 & $0 \cdot 214$ & $<0.001$ & -0.016 & $<0.001$ \\
\hline Race/colour self-reported (no white) & $-0 \cdot 118$ & $<0.001$ & $-0 \cdot 193$ & $<0.001$ & 0.395 & $<0.001$ \\
\hline Education (9 years or more) & 0.194 & $<0.001$ & 0.355 & $<0.001$ & -0.465 & $<0.001$ \\
\hline Ex-smoker & -0.085 & $<0.001$ & $-0 \cdot 116$ & $<0.001$ & -0.042 & 0.165 \\
\hline Current smoker & -0.034 & 0.310 & -0.456 & $<0.001$ & 0.082 & 0.027 \\
\hline Excessive alcohol consumption sporadic & -0.081 & 0.043 & -0.351 & $<0.001$ & -0.084 & 0.066 \\
\hline Moderate physical activity & -0.006 & 0.841 & 0.335 & $<0.001$ & $-0 \cdot 192$ & $<0.001$ \\
\hline Vigorous physical activity & -0.036 & 0.370 & 0.375 & $<0.001$ & -0.280 & $<0.001$ \\
\hline Overweight or obese & -0.001 & 0.684 & -0.005 & 0.102 & 0.001 & 0.825 \\
\hline Hypertension & -0.038 & 0.116 & -0.042 & $0 \cdot 174$ & -0.010 & 0.726 \\
\hline Diabetes & -0.006 & 0.843 & 0.055 & 0.134 & 0.064 & 0.059 \\
\hline Dyslipidaemia & 0.011 & 0.627 & 0.071 & 0.014 & $-0 \cdot 107$ & $<0.001$ \\
\hline
\end{tabular}

*A proportional odds model for each dietary pattern.

†Model adjusted by energy, dietary intake of total fat, saturated fat and fibre, and urinary sodium. 
Table 4 Multinomial regression models between Coronary Artery Calcium Score and dietary patterns. São Paulo (SP), Brasil, 2019

\begin{tabular}{|c|c|c|c|c|c|c|c|c|}
\hline & \multicolumn{4}{|c|}{ CAC $1-100($ reference $C A C=0)$} & \multicolumn{4}{|c|}{$\mathrm{CAC}>100($ reference $\mathrm{CAC}=0)$} \\
\hline & \multirow[t]{2}{*}{ OR } & \multicolumn{2}{|c|}{$95 \% \mathrm{Cl}$} & \multirow[t]{2}{*}{$P$} & \multirow[t]{2}{*}{ OR } & \multicolumn{2}{|c|}{$95 \% \mathrm{Cl}$} & \multirow[t]{2}{*}{$P$} \\
\hline \multicolumn{5}{|l|}{ Model $1^{*}$} & & & & \\
\hline Convenience pattern ${ }^{\star \star}$ & 0.85 & 0.72 & 0.99 & 0.050 & $1 \cdot 19$ & 0.97 & 1.48 & 0.100 \\
\hline Plant-based and dairy pattern ${ }^{\star *}$ & $1 \cdot 10$ & 0.97 & 1.25 & 0.129 & $1 \cdot 10$ & 0.93 & 1.31 & 0.259 \\
\hline Brazilian traditional pattern ${ }^{\star \star}$ & 0.91 & 0.79 & 1.04 & 0.176 & 0.65 & 0.54 & 0.79 & $<0.001$ \\
\hline \multicolumn{9}{|l|}{ Model $2 \dagger$} \\
\hline Convenience pattern ${ }^{\star \star}$ & 0.99 & 0.82 & $1 \cdot 20$ & 0.949 & $1 \cdot 31$ & 1.04 & 1.67 & 0.024 \\
\hline Plant-based and dairy pattern ** & $1 \cdot 13$ & 0.99 & $1 \cdot 30$ & 0.069 & $1 \cdot 10$ & 0.91 & $1 \cdot 32$ & 0.324 \\
\hline Brazilian traditional pattern ${ }^{\star \star}$ & 0.79 & 0.68 & 0.92 & 0.003 & 0.60 & 0.49 & 0.73 & $<0.001$ \\
\hline \multicolumn{9}{|l|}{ Model 3‡ } \\
\hline Convenience pattern ${ }^{\star \star}$ & 1.04 & 0.86 & 1.27 & 0.644 & 1.29 & 0.99 & 1.68 & 0.061 \\
\hline Plant-based and dairy pattern** & 1.09 & 0.93 & 1.28 & 0.279 & 0.99 & 0.79 & 1.25 & 0.951 \\
\hline Brazilian traditional pattern ${ }^{\star \star}$ & 0.92 & 0.78 & 1.09 & 0.354 & 0.77 & 0.61 & 0.97 & 0.026 \\
\hline \multicolumn{9}{|l|}{ Model $4 \S$} \\
\hline Convenience pattern ${ }^{\star \star}$ & 1.04 & 0.85 & $1 \cdot 27$ & 0.693 & $1 \cdot 31$ & 1.00 & $1 \cdot 71$ & 0.048 \\
\hline Plant-based and dairy pattern ${ }^{\star *}$ & $1 \cdot 16$ & 0.98 & 1.37 & 0.080 & 1.06 & 0.84 & 1.34 & 0.622 \\
\hline Brazilian traditional pattern ${ }^{\star *}$ & 0.92 & 0.77 & 1.09 & 0.321 & 0.76 & 0.60 & 0.97 & 0.025 \\
\hline \multicolumn{9}{|l|}{ Model 5II } \\
\hline Convenience pattern ${ }^{\star \star}$ & 1.04 & 0.85 & $1 \cdot 26$ & 0.699 & $1 \cdot 31$ & 1.00 & $1 \cdot 72$ & 0.047 \\
\hline Plant-based and dairy pattern ${ }^{\star *}$ & $1 \cdot 16$ & 0.98 & 1.37 & 0.075 & 1.08 & 0.85 & 1.36 & 0.546 \\
\hline Brazilian traditional pattern ${ }^{\star \star}$ & 0.92 & 0.77 & 1.09 & 0.333 & 0.78 & 0.61 & 0.99 & 0.040 \\
\hline \multicolumn{9}{|l|}{ Model 6ף } \\
\hline Convenience pattern ${ }^{\star \star}$ & 1.05 & 0.86 & 1.28 & 0.621 & 1.33 & 1.02 & $1 \cdot 74$ & 0.036 \\
\hline Plant-based and dairy pattern ${ }^{\star *}$ & $1 \cdot 17$ & 0.99 & 1.39 & 0.059 & 1.08 & 0.85 & 1.38 & 0.525 \\
\hline Brazilian traditional pattern ${ }^{\star *}$ & 0.91 & 0.76 & 1.08 & 0.285 & 0.76 & 0.60 & 0.97 & 0.027 \\
\hline
\end{tabular}

${ }^{*}$ Model adjusted by energy.

${ }^{* *}$ A proportional odds model for each dietary pattern.

†Model adjusted by energy, dietary intake of total fat, saturated fat and fibre, and urinary $\mathrm{Na}$

¥Model adjusted by all variables used in model 2 plus sex, age, race/colour and education.

$\S$ Model adjusted by all variables used in model 3 plus smoking, alcohol consumption and physical activity.

IIModel adjusted by all variables used in model 4 plus BMI.

१Model adjusted by all variables used in model 4 plus BMI, hypertension, dyslipidaemia and diabetes.

Studies have shown that the Mediterranean dietary pattern may be associated with less CAC progression ${ }^{(47)}$ and a lower incidence of $\mathrm{CVD}^{(48)}$. The protective effect of this diet cannot be attributed to a single food or nutrient, but rather to a combination of nutrients that have beneficial effects ${ }^{(49)}$. Similarly, the Brazilian traditional dietary pattern is characterised by the consumption of Brazilian traditional foods, which usually contain compound meals prepared with fresh and less processed foods. Cross-sectional studies conducted in the Brazilian population reported an inverse association between the Brazilian traditional dietary pattern (always combining rice and beans) and BMI and CVD risk factors ${ }^{(50-53)}$. The higher adherence to this dietary pattern could also imply healthier food habits and, consequently, a low consumption of the convenience dietary pattern food groups.

Although studies have shown that a higher intake of fruits and vegetables was associated with a lower risk of CAC progression ${ }^{(47)}$ and a lower prevalence of CAC $>0^{(54)}$, we did not find an association between plant-based and dairy dietary patterns and CAC scores. This lack of an association could be explained by the fact that, although we found a high dietary pattern for vegetables and fruits, the consumption of these food groups is usually low in the Brazilian population ${ }^{(55,56)}$.
In this sense, our results reinforce the importance of public health policies targeted to promote, encourage and facilitate the consumption and access to Brazilian traditional and fresh/unprocessed foods. Implementation of these policies is challenging since it involves many sectors and interests in the whole food system. However, the promotion of a healthier food environment through taxation, adequate food labelling, control of publicity and nutritional education are of utmost importance to promote health and prevent diseases.

The strengths of our study include its use of statistical methods, which provide a global analysis of diet, use of a validated FFQ, quality of the data collection and evaluation of CAC score, which provides the best non-invasive exam to predict cardiovascular event risk ${ }^{(57)}$. However, this study has some limitations. First, its cross-sectional design made it impossible to establish a temporal relationship between dietary patterns and CAC scores. Second, the factor analysis applied to identify dietary patterns requires an arbitrary decision and subjective interpretation of the factors. Factor analysis requires the researcher to define food groupings, number of factors to retain, and the interpretation and labelling of each dietary pattern. Third, dietary consumption was assessed using an FFQ, a self-reported method that could have introduced some bias, such as 
memory or social desirability, which could cause data misreporting. Finally, our results must be interpreted with caution when extrapolated to the general Brazilian adult population. Even though socio-economic status was considered in the adjusted analysis, the residual confounding of socio-economic factors cannot be dismissed. These data refer to a population of workers who share similar characteristics that differ from those of the general population of the country since this group had higher education, income levels and socio-economic status ${ }^{(19,20)}$

\section{Conclusion}

Our results showed that a dietary pattern composed of traditional Brazilian foods can play a protective role against CAC, while a convenience dietary pattern was positively associated with this outcome. Higher adherence to this Brazilian traditional dietary pattern could be important to reduce the risk of atherosclerotic calcification and prevent future cardiovascular events independent of sex, age, race/colour, lifestyle and the presence of non-communicable disease.

\section{Acknowledgements}

Acknowledgements: The authors thank the staff and participants of the ELSA-Brasil for their important contributions. Financial support: The ELSA-Brasil baseline study was supported by the Brazilian Ministry of Health, the Brazilian Ministry of Science and Technology and the Brazilian National Council for Scientific and Technological Development - CNPq. The research centre of São Paulo was also supported by the São Paulo Research Foundation - FAPESP. The institutions that supported the study had no role in the design, analysis or writing of this article. Conflict of interest: None. Authorship: D.M.M. and B.G. was responsible for study conception. B.G., J.A.T., R.O.S. and M.A.A. and D.M.M. contributed to the analysis and interpretation of data, manuscript drafting and critical manuscript revising. S.A., M.S.B., I.B., P.L. and D.M.M. contributed to critical review of the manuscript for important intellectual content. Ethics of human subject participation: This study was conducted according to the guidelines laid down in the Declaration of Helsinki, and all procedures involving study participants were approved by the Committee of Ethics in Research (approval number 189/2006). Written informed consent was obtained from all subjects/patients.

\section{References}

1. GBD Disease Injury I \& Prevalence Collaborators (2017) Global, regional, and national incidence, prevalence, and years lived with disability for 328 diseases and injuries for 195 countries, 1990-2016: a systematic analysis for the
Global Burden of Disease Study 2016. Lancet 390, 1211-1259.

2. Kerut EK, Hall ME, Turner MC et al. (2018) Coronary risk assessment using traditional risk factors with CT coronary artery calcium scoring in clinical practice. Echocardiography 35, 1216-1222.

3. Benjamin EJ, Virani SS, Callaway CW et al. (2018) Heart disease and stroke statistics-2018 update: a report from the American heart association. Circulation 137, e67-e492.

4. Pereira AC, Gomez LM, Bittencourt MS et al. (2016) Age, gender, and race-based coronary artery calcium score percentiles in the brazilian longitudinal study of adult health (ELSA-Brasil). Clin Cardiol 39, 352-359.

5. Budoff MJ, Achenbach S, Blumenthal RS et al. (2006) Assessment of coronary artery disease by cardiac computed tomography: a scientific statement from the American Heart Association Committee on Cardiovascular Imaging and Intervention, Council on Cardiovascular Radiology and Intervention, and Committee on Cardiac Imaging, Council on Clinical Cardiology. Circulation 114, 1761-1791.

6. Reilly MP, Wolfe ML, Localio AR et al. (2004) Coronary artery calcification and cardiovascular risk factors: impact of the analytic approach. Atherosclerosis 173, 69-78.

7. Pletcher MJ, Tice JA, Pignone M et al. (2004) Using the coronary artery calcium score to predict coronary heart disease events: a systematic review and meta-analysis. Arch Intern Med 164, 1285-1292.

8. Chaikriangkrai K, Jhun HY, Palamaner Subash Shantha G et al. (2017) Coronary artery calcium score as a predictor for incident stroke: systematic review and meta-analysis. Int J Cardiol 236, 473-477.

9. Nezarat N, Kim M \& Budoff M (2017) Role of coronary calcium for risk stratification and prognostication. Curr Treat Options Cardiovasc Med 19, 8.

10. Chun S, Choi Y, Chang Y et al. (2016) Sugar-sweetened carbonated beverage consumption and coronary artery calcification in asymptomatic men and women. Am Heart J 177, $17-24$.

11. Miranda AM, Steluti J, Goulart AC et al. (2018) Coffee consumption and coronary artery calcium score: cross-sectional results of ELSA-Brasil (Brazilian longitudinal study of adult health). J Am Heart Assoc 7, e007155.

12. Machado AD, Andrade GRG, Levy J et al. (2019) Association between vitamins and minerals with antioxidant effects and coronary artery calcification in adults and older adults: a systematic review. Curr Pharm Des 25, 2474-2479.

13. Nettleton JA, Steffen LM, Schulze MB et al. (2007) Associations between markers of subclinical atherosclerosis and dietary patterns derived by principal components analysis and reduced rank regression in the Multi-Ethnic Study of Atherosclerosis (MESA). Am J Clin Nutr 85, 1615-1625.

14. Bhat S, Mocciaro G \& Ray S (2019) The association of dietary patterns and carotid intima-media thickness: a synthesis of current evidence. Nutr Metab Cardiovasc Dis 29, 1273-1287.

15. Schulze MB \& Hoffmann K (2006) Methodological approaches to study dietary patterns in relation to risk of coronary heart disease and stroke. Br J Nutr 95, 860-869.

16. Michels KB \& Schulze MB (2005) Can dietary patterns help us detect diet-disease associations? Nutr Res Rev 18, 241-248.

17. Lloyd-Jones DM, Hong Y, Labarthe D et al. (2010) Defining and setting national goals for cardiovascular health promotion and disease reduction: the American Heart Association's strategic Impact Goal through 2020 and beyond. Circulation 121, 586-613.

18. Bhupathiraju SN \& Tucker KL (2011) Coronary heart disease prevention: nutrients, foods, and dietary patterns. Clin Chim Acta 412, 1493-1514.

19. Aquino EM, Barreto SM, Bensenor IM et al. (2012) Brazilian longitudinal study of adult health (ELSA-Brasil): objectives and design. Am J Epidemiol 175, 315-324. 
20. Schmidt MI, Duncan BB, Mill JG et al. (2015) Cohort profile: longitudinal study of adult health (ELSA-Brasil). Int $J$ Epidemiol 44, 68-75.

21. Andrade GRG, Gorgulho B, Lotufo PA et al. (2018) dietary selenium intake and subclinical hypothyroidism: a cross-sectional analysis of the ELSA-Brasil study. Nutrients 10, 693.

22. Bensenor IM, Griep RH, Pinto KA et al. (2013) Routines of organization of clinical tests and interviews in the ELSABrasil investigation center. Rev Saude Publica 47, Suppl. $2,37-47$.

23. Schmidt MI, Griep RH, Passos VM et al. (2013) Strategies and development of quality assurance and control in the ELSABrasil. Rev Saude Publica 47, Suppl. 2, 105-112.

24. Molina MDCB, Faria CPD, Cardoso LDO et al. (2013) Diet assessment in the Brazilian longitudinal study of adult health (ELSA-Brasil): development of a food frequency questionnaire. Rev Nutrição 26, 167-176.

25. Molina Mdel C, Bensenor IM, Cardoso Lde O et al. (2013) Reproducibility and relative validity of the Food Frequency Questionnaire used in the ELSA-Brasil. Cadernos Saude Publica 29, 379-389.

26. Bensenor IM, Goulart AC, Santos IS et al. (2016) Association between a healthy cardiovascular risk factor profile and coronary artery calcium score: results from the Brazilian longitudinal study of adult health (ELSA-Brasil). Am Heart $J$ 174, 51-59.

27. Agatston AS, Janowitz WR, Hildner FJ et al. (1990) Quantification of coronary artery calcium using ultrafast computed tomography. J Am Coll Cardiol 15, 827-832.

28. Azevedo CF, Rochitte CE \& Lima JAC (2012) Coronary artery calcium score and coronary computed tomographic angiography for cardiovascular risk stratification. Arqu Bras Cardiol 98, 559-568.

29. Marchioni DM, Claro RM, Levy RB et al. (2011) Patterns of food acquisition in Brazilian households and associated factors: a population-based survey. Public Health Nutr 14, 1586-1592.

30. McLean RM (2014) Measuring population sodium intake: a review of methods. Nutrients 6, 4651-4662.

31. Mamudu HM, Subedi P, Paul T et al. (2018) The associated risk factors for coronary artery calcium in asymptomatic individuals with and without diabetes in rural Central Appalachia. J Diabetes Complic 32, 900-905.

32. Mayer B, Lieb W, Radke PW et al. (2007) Association between arterial pressure and coronary artery calcification. J Hypertens 25, 1731-1738.

33. Craig CL, Marshall AL, Sjostrom M et al. (2003) International physical activity questionnaire: 12 -country reliability and validity. Med Sci Sports Exerc 35, 1381-1395.

34. Matsudo S, Araújo T, Matsudo V et al. (2001) International physical activity questionnaire (IPAQ): study of validity and reliability in Brazil. Rev Bras Ativ Saude 6, 5-18.

35. World Health Organization (1995) WHO Expert Committee on Physical Status: The Use and Interpretation of Anthropometry: Report of a WHO Expert Committee (Technical Report Series). Geneva: WHO.

36. Penalvo JL, Fernandez-Friera L, Lopez-Melgar B et al. (2016) Association between a social-business eating pattern and early asymptomatic atherosclerosis. J Am Coll Cardiol 68, 805-814.

37. Canhada SL, Luft VC, Giatti L et al. (2020) Ultra-processed foods, incident overweight and obesity, and longitudinal changes in weight and waist circumference: the Brazilian longitudinal study of adult health (ELSA-Brasil). Public Health Nutr 23, 1076-1086. doi: 10.1017/S1368980019002854.
38. Sichieri R, Coitinho DC, Monteiro JB et al. (2000) Recomendações de alimentação e nutrição saudável para a população brasileira [Dietary guidelines to healthy nutrition for Brazilian population]. Arquivos Brasileiros Endocrinologia Metabologia 44, 227-232.

39. Mattei J, Hu FB \& Campos H (2011) A higher ratio of beans to white rice is associated with lower cardiometabolic risk factors in Costa Rican adults. Am J Clin Nutr 94, 869-876.

40. Thompson SV, Winham DM \& Hutchins AM (2012) Bean and rice meals reduce postprandial glycemic response in adults with type 2 diabetes: a cross-over study. Nutr J 11, 23 .

41. Havemeier S, Erickson J \& Slavin J (2017) Dietary guidance for pulses: the challenge and opportunity to be part of both the vegetable and protein food groups. Ann NY Acad Sci 1392, 58-66.

42. Soliman GA (2019) Dietary fiber, atherosclerosis, and cardiovascular disease. Nutrients 11, 1155.

43. Viguiliouk E, Glenn AJ, Nishi SK et al. (2019) Associations between dietary pulses alone or with other legumes and cardiometabolic disease outcomes: an umbrella review and updated systematic review and meta-analysis of prospective cohort studies. Adv Nutr 10, S308-S319.

44. Viguiliouk E, Blanco Mejia S, Kendall CW et al. (2017) Can pulses play a role in improving cardiometabolic health? Evidence from systematic reviews and meta-analyses. Ann NY Acad Sci 1392, 43-57.

45. Andrade GC, da Costa Louzada ML, Azeredo CM et al. (2018) Out-of-home food consumers in Brazil: what do they eat? Nutrients 10, 218.

46. Kim Y, Je Y \& Giovannucci EL (2020) Association between dietary fat intake and mortality from all-causes, cardiovascular disease, and cancer: a systematic review and meta-analysis of prospective cohort studies. Clin Nutr. Published online: 14 July 2020. doi: 10.1016/j.clnu.2020.07. 007.

47. Frolich S, Lehmann N, Weyers S et al. (2017) Association of dietary patterns with five-year degree and progression of coronary artery calcification in the Heinz Nixdorf Recall study. Nutr Metab Cardiovasc Dis 27, 999-1007.

48. Tong TY, Wareham NJ, Khaw KT et al. (2016) Prospective association of the Mediterranean diet with cardiovascular disease incidence and mortality and its population impact in a non-Mediterranean population: the EPIC-Norfolk study. BMC Med 14, 135.

49. Korakas E, Dimitriadis G, Raptis A et al. (2018) Dietary composition and cardiovascular risk: a mediator or a bystander? Nutrients 10, 1912.

50. Castro MA, Baltar VT, Marchioni DM et al. (2016) Examining associations between dietary patterns and metabolic CVD risk factors: a novel use of structural equation modelling. Br J Nutr 115, 1586-1597.

51. Cunha DB, de Almeida RM, Sichieri R et al. (2010) Association of dietary patterns with BMI and waist circumference in a low-income neighbourhood in Brazil. BrJ Nutr 104, 908-913.

52. Sichieri R (2002) Dietary patterns and their associations with obesity in the Brazilian city of Rio de Janeiro. Obes Res 10, 42-48.

53. Olinto MT, Gigante DP, Horta B et al. (2012) Major dietary patterns and cardiovascular risk factors among young Brazilian adults. Eur J Nutr 51, 281-291.

54. Miedema MD, Petrone A, Shikany JM et al. (2015) Association of fruit and vegetable consumption during early adulthood with the prevalence of coronary artery calcium after 20 years of follow-up: the Coronary Artery Risk 
Development in Young Adults (CARDIA) study. Circulation 132, 1990-1998.

55. Instituto Brasileiro de Geografia e Estatística (2020) Brazilian National Household Budget Survey 2017-2018: Brazilian National Dietary Survey. Rio de Janeiro: IBGE.

56. Silva LESD \& Claro RM (2019) Time trends in the consumption of fruits and vegetables among adults in Brazilian state capitals and the Federal District, 2008-2016. Cadernos Saude Publica 35, e00023618.

57. Geisel MH, Bauer M, Hennig F et al. (2017) Comparison of coronary artery calcification, carotid intima-media thickness and ankle-brachial index for predicting 10-year incident cardiovascular events in the general population. Eur Heart J 38, 1815-1822. 